\title{
An Empirical Examination of the Determinants of Food Insecurity among Rural Farm Households: Evidence from Kindo Didaye District of Southern Ethiopia
}

Ermias Ganamo Gazuma*

Department of Economics, Wolaita Sodo University, Wolaita Sodo, Addis Ababa, Ethiopia

\begin{abstract}
The major aim of this study was to assess the determinants of food insecurity among rural farm households in Kindo Didaye district, Ethiopia. Data for the study was obtained from 160 randomly selected farm households by using structured questionnaire. To select sample respondents, the stratified sampling technique was used. The adapted FGT index, Coping Strategy index and binary logit model were used for data analysis. The finding from FGT index revealed that 70.62 percent of households in the study area were found food insecure. The depth and severity of food insecurity were found $37 \%$ and $25.6 \%$, respectively. The logistic regression model result showed that factors such as household size, livestock ownership of households, land size, opportunity to off-farm activities, and distance to the local market were found significant factors influencing households' food security status. Thus, promotion of family planning, enhancing livestock packages, and creation of rural employment opportunities are recommended.
\end{abstract}

Keywords: Ethiopia; Kindo Didaye; Food security; FGT; Coping strategies; Logistic regression

\section{Introduction}

Food security exists when all people, at all times, have physical, social and economic access to sufficient, safe and nutritious food to meet their dietary needs and food preferences for an active and healthy life [1]. The International commitment to the right to food was acknowledged in 1948 as part of the Universal Declaration of Human Rights (UDHR). As article 25 of UDHR puts it "everyone has the right to a standard of living adequate for the health and well-being of himself and his family including food, clothing, housing and medical care and necessary social services, and the right to security in the event of unemployment, sickness, disability, widowhood, old age or other lack of livelihood in circumstances beyond his control" [2]. Nevertheless, the latest FAO estimates indicates that about 805 million people in the globe are chronically undernourished in between the years 2012-14, of which an estimated 791 million chronically hungry people were from developing countries. This means that about one in every nine people in the world and one in eight people in developing regions still has insufficient food for an active and healthy life [3].

Sub-Saharan Africa has become home to more than a quarter of the worlds' undernourished people, owing to around one in four people in the region remains undernourished. This is perhaps one of the worst violations of human dignity. The global nutrition report (2014) also highlighted the increasing human and economic costs associated with under nutrition in the Sub-Saharan region. The human costs are high in terms of preventable mortality and morbidity. The economic costs are also large; Gross Domestic Product (GDP) totals in Africa and Asia are less than 90 percent of what they would be in the absence of under nutrition.

Ethiopia is one of the poorest countries in the world with more than 27.8 percent of its population is believed to be living below poverty ${ }^{1}$ line in the year 2012 and is ranked 173 out of 182 countries in Human Development Index (HDI) [4,5]. The country is typically an agrarian

1 "Poverty is a human condition characterized by the sustained or chronic deprivation of the resources, capabilities, choices, security and power necessary for the enjoyment of an adequate standard of living and other civil, cultural, economic, political and social rights [3]." economy and agriculture is the source of livelihood for more than 80 percent of population in the country. The sector accounts for about 44 percent of the GDP, generates almost 75 percent of exports and will remain a major source of inputs for the emerging industrial sector [6]. Ethiopia's macro-economic strategy, the Growth and Transformation Plan $(G T P)^{2}$ 2010-2015, has indicated that "...the objective to become a food secure and middle income country can only be achieved, amongst other factors, through increased agricultural productivity, by creating an enabling environment for enhanced private investment and agriculture-led industrialization" [7]. In this regard, it is likely that the failure or success of the agricultural sector can have strong influence on the extent of economic growth and the living conditions of the people in Ethiopia. However, the sector remains dominated by rain-fed subsistence farming in which droughts periodically reverse performance gains, with devastating effects on household food security [5].

Many reports have declared that the country has emerged as one of the fastest growing economies globally with an average GDP growth of 11 percent per annum over the last ten years. Nonetheless, almost 35 percent of the population is estimated to be undernourished and living below the food poverty line, unable to afford the minimum caloric intake for a healthy and active life [8,9]. Another demonstration for the prevalence of severe food insecurity problem in Ethiopia could be

${ }^{2}$ GTP is a medium term strategic framework for the five-year period (2010/11 2014/15) which is directed towards achieving Ethiopia's long term vision and sustaining the rapid and broad based economic growth and eventually to end poverty.

*Corresponding author: Ermias Ganamo Gazuma, Department of Economics Wolaita Sodo University, Wolaita Sodo, Addis Ababa, Ethiopia; Tel: +251 911929717; E-mail: ermigana@yahoo.com

Received February 20, 2018; Accepted March 20, 2018; Published March 27 2018

Citation: Gazuma EG (2018) An Empirical Examination of the Determinants of Food Insecurity among Rural Farm Households: Evidence from Kindo Didaye District of Southern Ethiopia. Bus Eco J 9: 345. doi: 10.4172/2151-6219.1000345

Copyright: (c) 2018 Gazuma EG. This is an open-access article distributed under the terms of the Creative Commons Attribution License, which permits unrestricted use, distribution, and reproduction in any medium, provided the original author and source are credited. 
through looking at the level of stunting ${ }^{3}$, wasting ${ }^{4}$ and underweight $t^{5}$ of children less than five years of age. The 2014 Mini Demographic and Health Survey of Ethiopia has found that nationally 40 percent of children under age five were stunted (i.e., they are considered as short, or chronically malnourished), 9 percent were wasted (i.e., they are thin, or acutely malnourished), and 25 percent were classified as underweight. Under-nutrition is predominantly rural in the country: stunting and underweight rates are (42 and 27 percent respectively) in rural areas, significantly higher compared to (24 and 13 percent) in urban areas [10].

Similarly, Kindo Didaye, one of the twelve districts of Wolaita Zone located in SNNPR state, Ethiopia is famously known for recurrent hunger which is aggravated by drought and flood. Moreover, high family size coupled with very small; perhaps fragmented arable land which is characterized by hills and mountains is the main feature of the area. The district was also one of the major emergency food aid recipients in the country [11]. The continued huge youth rural-urban migration is another implication for the prevalence of seemingly chronic food insecurity in this particular area. Moreover, lack of means of production, and large family size as high as 300 people per square $\mathrm{km}$ are the main characteristics of rural farm households in the region [11]. Different literatures revealed that in areas like Kindo Didaye, where 'enset' (false banana) is used as staple food, the land size needed for cereal production is 0.56 hectares to meet the minimum level of food needs for an average household [12]. However, the majority of smallholder farmers operate on less than one hectare in the country, with more than 40 percent on less than half a hectare and this is inadequate to sustain a family $[5,13]$.

Considerable scholars have studied the issue of food insecurity at a national, regional, and household level in Ethiopia [10,12,14-23]. Some of these studies were undertaken at the national level and others are concentrated on household level analysis at a district level $[7,10]$. The studies undertaken at the national level missed the assertion that "food security at the national level does not guarantee food security at the household or even at an individual level", and cannot be used as a reference for the present study area. Food security analysis has four fundamental dimensions, namely availability, access, utilization and stability or vulnerability. Majority of studies undertaken even at household level have failed to explicitly indicate the type of food security dimension adopted in their analysis. Besides, as per the knowledge of the researcher, food insecurity situation and its principal determinants in the study area is not well documented, perhaps non-existent. Therefore, the present study is aimed at filling the above gaps via adding body of knowledge to the existing literatures by examining the food insecurity situation and its determinants among rural farm households in Kindo Didaye district of Wolaita zone, southern Ethiopia. The rest of the paper is organized as follows: Section 2 describes methodology used in the study. Section 3 constitutes results and discussion; and section 4 concludes the paper.

${ }^{3}$ Stunting or low height-for-age is defined as having a height at least two standard deviations below the median height for a reference population. It provides an indicator of linear growth retardation and cumulative growth deficits in children. As such, it represents the long-term effects of malnutrition.

${ }^{4}$ Wasting is based on standardized weight-for-height, and low values can be a measure of acute malnutrition in some situations. Hence, this index describes current nutritional status.

${ }^{5}$ Underweight or low weight-for-age is similarly defined. Weight-for-age is a composite index of height-for-age and weight-for-height. It takes into account both chronic and acute malnutrition [10].

\section{Materials and Methods}

\section{Description of the study area}

Kindo Didaye district is located in Southern Province of Ethiopia and is bordered by the Dawuro zone on the North, Gamo Gofa zone on the South; the districts of a to the South east and Kindo Koysha to the North East (see Map below). Geographically the district is located between $6^{\circ} 67^{\prime}$ and $6^{\circ} 87^{\prime}$ Latitude/North/, and $37^{\circ} 22^{\prime}$ and $37^{\circ} 49^{\prime}$ Longitude/East/ covering a total land area of 381 square kilometers. It consists of 20 rural and 2 urban kebeles with 26,720 households and its population size is estimated to be 121, 984 in the year $2014 / 15$. The mean annual temperature is between $15.1^{\circ} \mathrm{C}$ and $27.5^{\circ} \mathrm{C}$; and the mean annual rainfall is $1400-1600 \mathrm{~mm}$. The district has a diverse topography, with an altitude that varies between 1400 and 2500 meters above sea level (m.a.s.l). The main agro climatic zones of the region are lowland, mid-highland, and highland. Households in the district own fragmented agricultural land; and mixed farming is the main livelihood activity. The farming season is dependent on the summer ('Kiremt') rains that start in June and last until September and the main hunger season is from February to June [24].

\section{Data types, sources and methods of data collection}

Primary data was collected and utilized so as to achieve objectives of the study. In this regard, qualitative and quantitative data pertaining to social, demographic and economic aspects of farm households in the study area was gathered. The reference period for the data was a year starting from March, 2014 to February, 2015. The main instrument used for primary data collection was well-structured questionnaire administered by the researcher and trained enumerators. The questions were prepared in English and translated into Wolaita local language. In addition; Key Informant Interview (KII) and Focus Group Discussion (FGD) were used to collect qualitative data. Agricultural development agents and community leaders were the major participants in FGD and KII.

\section{Sampling technique and sample size}

In the underlying study, stratified sampling technique was employed in order to accommodate the agro-ecological heterogeneity in the study area. Firstly, the 22 kebeles in the district were divided into three agro-ecological Zones such as highland, mid-highland and lowland. Following this, one sample kebele was selected from each stratum by using simple random sampling techniques. Lastly, proportional probability sampling technique was utilized to select sample households from selected three rural Kebeles. Accordingly, 23 sample households from Wamura Berkoshe kebele, 64 from Zero kebele, and 73 from Lasho kebele were included for the study, each representing mid-highland, lowland, and highland agro-climatic zones, respectively. Thus, the total samples of 160 households were used for the study. This sample size was determined based on previous work by Kothari. Following Kothari [25] the formula for sample size is given as:

$$
n=\frac{z^{2} \cdot p \cdot q \cdot N}{e^{2}(N-1)+z^{2} \cdot p \cdot q}
$$

where,

$\mathrm{n}=$ the minimum number of sample size within the range of acceptable error margin;

$\mathrm{N}=3970$ (the total sum of households in the selected three kebeles as of June, 2014); 

level);

$\mathrm{Z}=1.645$ (area under normal curve for the 95 percent confidence

$\mathrm{e}=0.05$ (acceptable error or the precision);

$\mathrm{p}=0.75$ (proportion of sample population assumed to be food insecure); and

$\mathrm{q}=0.25$ (the proportion of sample population assumed to be food secure).

Thus, introducing these values into equation (1) above yields the sample size of 193 households. However, 33 observations with inconsistent response were dropped during data screening stage. Thus, 160 observations were used for the study.

\section{Method of determining food insecurity line}

An important question in practice is whether one should construct food insecurity line based on income or consumption data. It is usually argued that while the rural poor are often found to be constrained in their ability to smooth income, consumption is still found to be less volatile over time and hence it is less vulnerable to seasonality and life-cycle [26]. Moreover, the reliability of income data in subsistence farming where record keeping is limited, perhaps non-existent is always doubtful. Consumption is also likely to be the better measure of current welfare on both theoretical and practical grounds [27]. Thus, this study has considered collection of data on consumption as an ideal measure for the estimation of food insecurity line.

Various methods are used in the calculation of food security status in literature. However, Direct Calorie Intake (DCI) method is adopted for this study. This method estimates the number of calories available for consumption by adult equivalent household members over a defined period of time. Hence, the seven day recall for one full year reference period was used to collect consumption data in the study. A popular practical method of setting food insecurity line using this method proceeds by computing the consumption level of dynamic set of food baskets by sample households; then converting all quantities into kilogram to have a common unit of measurement; and finally converting these quantities into kilocalories using the standard caloric conversions prepared by Ethiopian Health and Nutrition Research Institute [28]. Accordingly, households with per capita energy intake less than the standard per capita requirement of 2,200 kilocalories were considered as food insecure and above this threshold were considered as food secure. Algebraically, this can be expressed as:

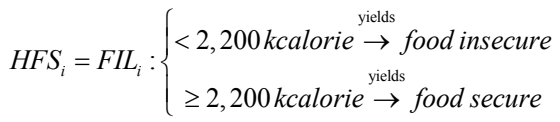

where HFS, refers to food security status of the $i^{\text {th }}$ household, and FIL represents the food insecurity line for $i^{\text {th }}$ household, $\mathrm{i}=1,2,3 \ldots 160$.

\section{Measuring the extent of food insecurity}

The Foster et al., [29] class of poverty measure was adapted to assess the extent of food insecurity among the established food insecure sample households. The mathematical expression of the FGT index is specified as follows:

$$
P_{\alpha}=\frac{1}{N} \sum_{i=1}^{q}\left[\frac{\left(Z-Y_{i}\right)}{Y_{i}}\right]^{\alpha}
$$

Where, $\mathrm{Z}$ is the food insecurity line, $Y_{i}$ is the per capita calorie intake of household $i$ adjusted for per adult consumption expenditure, $\mathrm{N}$ is the total sample size, and $q$ is the total number of food insecure households below the food insecurity line. The food insecurity aversion parameter ' $\alpha$ ' reflects the concern attached to the proportionate shortfall from the food insecurity line. If $\alpha=0$ then, FGT measures corresponds to the head count index (incidence of food security) in which no concern for the depth of the shortfall is shown. In other words, it is the share of sample households whose food expenditure per adult equivalent falls below the food insecurity line. If $\alpha=1$ then, FGT refers to the mean distance that divorces the food insecure household from the food insecurity line, commonly called the depth of food insecurity. It provides information regarding the distance between the food insecurity line and each household's food expenditure per adult equivalent thereby reflecting the per capita cost of eliminating food insecurity. If $\alpha=2$ then, FGT measures the severity of food insecurity. It takes into account not only the distance separating the food insecure from food insecurity line, but also inequality among the food insecure households.

\section{Method of determining coping strategy index}

People adopt a range of coping strategies in response to shocks. The Coping Strategies Index (CSI) and Household Food Insecurity Access Scale (HFIAS) methods can be applied to examine how the households respond to the presence of food shortages. Both approaches are relatively simple, quick to use, and use almost similar generic questions [30-32]. There exists no binding rule to choose one over the other. CSI was found through long-term research studies to reflect current food security status, and was also found to be a good predictor of vulnerability to future food insecurity [31]. Following this, the underlying study has applied Coping Strategy Index (CSI) as a tool for the analysis of households' coping strategies.

A simple question "What do you do when you don't have enough food, and don't have enough money to buy food?" comprises the basis of the CSI tool [30]. The first task was identifying the locally relevant coping strategies through focus group discussion with members of the local Community in the study area. Following, the frequency and the severity of these coping behaviors were then determined. In order to rank the severity level, the individual coping behaviors were grouped according to similar levels of severity and weight was assigned to each group from least severe to most severe [33]. A range of weights from 1 to 4 were used. Finally, information on the frequency and severity was then combined in a single score, the Coping Strategies Index, which is an indicator of the household's food security status. The steps described herein to compute the Coping Strategy Index can be summarized in a simple algebraic form as follows:

$$
C S I_{j}=\sum_{i=1}^{n} F_{i} S_{i}
$$

where; $\mathrm{CSI}_{i}=$ shows the Coping Strategy Index of $j^{\text {th }}$ sample household, $j=1,2,3, \ldots, 160 ; F_{i}=$ is the frequency of the $i^{\text {th }}$ coping strategy taken by a household in the past thirty days; $\mathrm{S}_{\mathrm{i}}=$ represents the severity weight attached to $i^{\text {th }}$ coping strategy, and $\mathrm{n}=$ refers to the maximum number of coping strategies used by $j^{\text {th }}$ sample household.

\section{Econometric model specification}

An essential shortcoming of classical linear regression model is that it only considers numerical (continuous) data for dependent variable. But, many interesting variables are categorical in practice. Following this, a regression analysis in which the dependent variable involves qualitative responses (i.e., 'yes' or 'no' type) was usually done using discrete choice models. For the purpose of this study, the dependent variable y is defined to indicate whether a household is food insecure 
or not. In this case, we can let $y=1$ denote a household is food insecure and $\mathrm{y}=0$, otherwise.

Wooldridge [34] mentioned three approaches to develop probability model for a binary response dependent variable. These include Linear Probability Model (LPM), Logit Model and the Probit or Normit Model. In this study, Logit model was used since it has several advantages over other methods. One of the merits of this model compared to other methods is that the independent variables can take on any form since logistic regression makes no assumptions about the distribution of the independent variables. Unlike ordinary least square regression, logistic regression does not require normally distributed variables, does not assume homoscedasticity, the parameter estimates under logit model are fully efficient and generally it has relatively flexible data requirements.

The LPM is plagued by several problems, such as non-normality of error term, heteroscedasticity of error term, and generally the lower R2 values [35]. Nonetheless, the logit and probit models are quite similar in many applications except that the logit model involves cumulative logistic function and probit model follows the normal cumulative distribution function. Though there is no exciting reason to choose one over the other, due to comparative computational simplicity, the logit model was used in this study to investigate the key explanatory factors that may influence the rural farm households' food security status. Following Gujarati [35], the functional form of cumulative logit model is specified as follows:

$$
P_{i}=E\left(y=1 \mid x_{i}\right)=\frac{1}{1+e^{-\left(x^{\prime} \beta\right)}}
$$

For simplicity,

$$
P_{i}=E\left(y=1 \mid x_{i}\right)=\frac{1}{1+e^{-z_{i}}}=\frac{e^{z}}{1+e^{-z}}
$$

Where, $Z_{i}=x^{\prime} \beta=\beta_{0}+\beta_{1} x_{1}+\beta_{2} x_{2}+\ldots+\beta_{n} x_{n}$.

$\beta_{0}$ is an intercept, $\beta_{1}, \beta_{2}$ and $\beta_{n}$ are slope coefficients and $x_{1}, x_{2}$ and $x_{n}$ are related household characteristics.

Eqn. (6) represents (cumulative) logistic distribution function. Nonlinearly related to $\mathrm{Z}_{\mathrm{i}}$ (i.e., $\mathrm{x}_{\mathrm{i}}$ ) thus satisfying the following two requirements: Firstly, as $z_{i} \rightarrow+\infty, e^{-z_{i}}$ tends to zero. In the second scenario, $z_{i} \rightarrow-\infty, e^{-z_{i}}$ increases indefinitely. But it seems that in satisfying these requirements, we have created an estimation problem because $P_{i}$ is nonlinear not only in $x$ but also in $\beta^{\prime}$ s as can be seen clearly from equation (5) above. This means that we cannot use the familiar OLS procedure to estimate the parameters. But this problem is more apparent than real because eqn. (5) can be made linear, which can be shown as follows.

If $P_{i}^{\prime}$ is the probability of household being food insecure, is given by eqn. (6), then $\left(1-P_{i}\right)$, the probability of household being food secure can be expressed as:

$$
1-P_{i}=\frac{1}{1+e^{z_{i}}}
$$

Therefore, we can write

$$
\frac{P_{i}}{1-P_{i}}=\frac{1+e^{z_{i}}}{1+e^{-z_{i}}}=e^{z_{i}}
$$

Eqn. (8) shows the odds ratio in favor of household being food insecure; that is the ratio of the probability that a household is likely to be food insecure to the probability that it will be food secure. If we take the natural logarithm of equation (8), we obtain the following equation:

$$
\mathcal{L}_{i}=\ln \left(\frac{P_{i}}{1-P_{i}}\right)=z_{i}=\beta_{1} x_{1}+\beta_{2} x_{2}+\ldots+\beta_{n} x_{n}
$$

That is, $L_{i}$, is the natural logarithm of the odds ratio, is not only linear in the explanatory variables, $\mathrm{x}_{\mathrm{i}}$ 's, but also in the parameters from the estimation point of view. $L$ is called the logit, and hence the name logit is given for models like in eqn. (9) above.

Now for estimation purpose, by introducing the disturbance term $\varepsilon_{\mathrm{i}}$, the logit model can be written as follows:

$$
\mathcal{L}_{i}=\ln \left(\frac{P_{i}}{1-P_{i}}\right)=\beta_{0}+\beta_{1} x_{1}+\beta_{2} x_{2}+\ldots+\beta_{i} x_{i}+\epsilon_{i}
$$

It is easy to see that the log-odds ratio is: $\operatorname{Ln} \mathcal{L}=Z_{i}=x^{\prime} \beta$. Accordingly, the coefficient $\beta$ measures the change in log-odds ratio for a unit change in a covariate. By inspecting the sign of independent variable's coefficient of estimate, the influence of that variable on the probability of a household being food insecure can be determined. However, the parameter estimates of the logit model provide only the direction of the effect of independent variables on the dependent variable. As such, these estimates represent neither the actual magnitude of change nor the probabilities. Differentiating eqn. (10) with respect to the covariates provides the marginal effects of the characteristics on the probabilities and specified as follows:

$$
\frac{\partial P_{i}}{\partial x_{i}}=P_{i}\left(1-P_{i}\right) \beta_{i}
$$

Therefore, eqn. (11) represents the marginal effects of the logit model. Hence, the maximum likelihood estimation method was applied in this study.

\section{Description of variables and their expected signs}

Dependent variable: The dependent variable for the study was the household food security status (HFS) which is proxied by food calorie consumption. It is a binary variable which was assigned value label ' 1 'for a household who was found food insecure and'0' otherwise.

Explanatory variables: These are variables that are expected to, either positively or negatively, influence the household's food security in the study area. The followings are selected independent variables included in the model as described above.

Agroecology (AGROeco): This is a dummy variable such that value 0 was assigned for mid-highland, value label 1 was set for highland, and value label 2 was allocated for lowland each representing the agro-climatic zone respondent belongs to. It was hypothesized that households who lives in lowland were more likely to be food insecure.

Age of Household head (HHHage): This is a continuous variable. Since household heads become more experienced with age and acquire more knowledge and physical assets, it may affect food security in a positive way. Some studies have found that the higher the age of the household head, the more stable the economy of the farm household. This is because older household heads have relatively more experience with their social and physical environment as well as with farming activities. A priori expectation was that age of the household head and the households' food security status would have a positive relationship.

Sex of the household head (HHHsex): Based on different empirical findings, the researcher's priori expectation is that femaleheaded households are likely to be more food insecure than maleheaded households. This is a dummy variable denoted by 1 for male headed households and 0 otherwise. 
Education of household head (HHHeduc): It is a dummy variable. It takes the value 1 for the respondent found literate and 0 otherwise. For this study, the one who can read and write was taken as literate. The expectation was that there would be a likely positive relationship between literacy status of the household head and his subsequent food security status.

Household size (HHsize): Household size is a continuous variable and refers to the total number of Household members who live in the same home during the survey period. Here the total number of a household is converted into the standard adult equivalent unit. Some studies see household size as being inversely related with food security by assuming larger households need more resources to full fill their food needs, whereas other studies see a positive association in expectation that the larger households have a larger labor force that contributes to the family food production. In the present study, it is hypothesized that as size of the household increase, the probability of being food insecure also increases.

Dependency ratio (DPNDCYratio): This is a continuous variable and can be obtained by dividing inactive labor force $(<15$ year and $>64$ years old) to the active labor force (between 15 and 65 years) in a household. The expectation was that dependency ratio and food insecurity would have a likely positive relationship.

Farm land size (FLsize): This is a continuous variable and refers to the total farmland owned by the household and measured in hectares. The smaller the farmland size owned by the household the smaller would be the level of production and the household is more likely to be food insecure.

Livestock ownership (TLU) ${ }^{7}$ : It is a continuous variable and measured in Tropical Livestock Unit (TLU). A household's level of farm resources (e.g., livestock) is expected to affect its ability to survive in period of sudden changes in production, prices, income or unforeseen events that create the need for additional expenditures. The priori expectation was that the smaller the size of livestock a household has, the more would be the probability of a household being food insecure.

Off-farm activities (OFFARM): This is a dummy variable for which value 1 is assigned for the respondent who gets off-farm income and 0 otherwise. Households who don't participate in off farm income generating activities were expected to face food deficit if their farm income is found not sufficient enough to cover households' food and non-food needs.

Distance to the nearby local market (DSTNC): This is a continuous variable and measured by the distance from a household's residence to the nearest local market (walking distance in minutes). It is presumed that households who are closer to local markets are expected to have easier access to undertake transaction and hence less likely to be food insecure.

Remittance (REMITT): Income from families working elsewhere is an important determining factor of rural households' food security status. According to the previous knowledge of the researcher, substantial numbers of households in the study area have income from remittances. It is hypothesized that getting financial support

${ }^{6}$ Here the education level of the household head is conceptualized as whethe he/she can read and/or write. The one who, at least, attended primary school is considered as literate and otherwise illiterate.

${ }^{7}$ The total number of livestock ownership is measured by Tropical Livestock Unit (TLU). TLU is a "hypothetical" animal of $250 \mathrm{~kg}$ live weight. As such, it is an index number that aggregates the different types of livestock a household owned to a single number using a standard conversion factor. from migrant family members living elsewhere is likely and positively be related to the food security status of the household. It is a dummy variable taking value 1 for a sample household who gets remittance income and 0 otherwise.

Participation in social institution (SOCIALinst): This is an aspect of social capital a household access by being a member of various community organizations like networks, social relations, and associations. It is a dummy variable which is proxied by 'Equb' and assigned value 1 for households who participates in 'Equb'; and 0 otherwise.

Access to credit (CREDIT): This is a dummy variable which was assigned value label 1 for the respondents who are found to have access to credit and 0 otherwise. Access to credit is expected to have a positive influence as it enables farmers to solve short term liquidity constraints, in turn influencing food production. Credit can also be used as a consumption smoothing mechanism in the event of food shortage in the household. It is therefore hypothesized that households with credit access will have less chance of being food insecure than their counter parts.

Access to extension service (EXTensn): This is also a dummy variable in that it has assigned the value label 1 for households who have access to adequate agricultural extension service and 0 otherwise. It indicates the adequacy of training and advisory service provided by government's development agents in the reference year. Farmers well visited by these agents are likely to improve their knowledge in using and managing their inputs compared to those who don't get the service and this can probably improve their productivity which can minimize the probability of being food insecure. On the basis of this analogy, it prior expectation was that getting adequate extension service and the subsequent household food security status would be inversely related.

Productive safety nets participation (PSNP): This is one of the government's food security programs that targets on the most affected groups of the society. It is dummy variable which takes value 1 for the respondent who participates in safety net programs and 0 otherwise. It might have either positive or negative relationship with households food security status depending of the adequacy of the program.

Technology adoption (TECHadopt): This is a dummy variable for which value label 1 is assigned for the respondents found to adopt technology like chemical fertilizers, pesticides, and improved seed varieties; and 0 otherwise. Here chemical fertilizer was taken as a proxy for technology adoption as the rest of technologies were insufficiently made available for farm households in the study area. The prior expectation is that households who adopt the existing technologies were expected to be food secure than those who didn't adopt.

\section{Results and Discussion}

\section{Summary of results using descriptive statistics}

To determine the Household's Food security Status (HFS), the Direct Calorie Intake (DCI) method was used for reasons discussed in the previous section. The survey result has showed that from 160 sample households, 113 (70.62\% households were food insecure and only 47 (29.38\%) were found food secure. Associated with this, the result has underlined the existence of a mean dietary calorie consumption difference between food secure and food insecure households in the study area. The $t$ statistic of 18.4995 with prob $>t=0.0000$ confirmed that there is statistically significant difference between food insecure and food secure households with respect to calorie consumption (see 
Table 1 below for details). The finding also revealed that the per capita dietary energy available for the households varies across agro-climatic zones. The mean value shows that the households in mid-highland areas were found better side with the average daily per capita calorie supply of $2064.4035 \mathrm{kcal}$ per capita AE per day. The higher amount of mean per capita kilocalorie for mid-highland agro-climatic zone may be attributed to the fairly better rainfall distribution and the relative importance of this particular area in terms of several production seasons in a year.

The average dietary energy available for households from highland and lowland is $1828.7523 \mathrm{kcal}$ and $1623.5377 \mathrm{kcal}$, respectively (see Table 2 for detail). Hence, the level of calorie available for households in mid-highland, highland and lowland indicates that, on average, there is a deficit of $6.16,16.87$, and 26.2 percent, respectively, in order to fulfill the minimum recommended daily energy requirement for survival. With the highest percentage of calorie deficit in the reference year, households from lowland areas were found to be the most food insecure in the study area. With the F statistic of 6.66 and prob $>F=0.0017$, it can be concluded that there is statistically significant difference in dietary calorie consumption across households from different agro-ecological zones in the study area. This may be due to crop failures and the livestock diseases as reported by majority of sample households from that particular agro-climatic zone during the survey period. This is also consistent with the result from focus group discussion.

\section{The correlates of household characteristics and decomposable FGT class of food insecurity measure}

This section tries to examine the extent of food insecurity among food insecure sample households using an adapted Foster-GreerThorbecke (FGT) class of food insecurity measures. The finding of this study revealed that the head count ratio, the food insecurity gap (short-fall), and the squared food insecurity gap (severity of food insecurity) were estimated to be 70.62 percent, 37 percent, and 25.6 percent, respectively in the study area. This implies 70.62 percent of the sample households cannot meet the minimum energy requirement recommended for healthy and active life. The FGT1 or P1 index shows the gap (depth) of food insecurity or the average short fall of food energy from the minimum amount of deity energy required for food insecure households. In other words, it measures the total amount of kilocalorie necessary to remove the food insecurity. In the present study, each food insecure household needs, on average, 37 percent extra daily caloric consumption to bring them up to the minimum recommended daily caloric requirement level (Table 3 ).

The FGT2 or P2 index of food insecurity indicates the severity of food insecurity by giving more weight for the more deprived households; i.e., households with higher amount of food energy deficit from the recommended minimum allowance are given more weight in the computation of average level of shortfall of per capita kilocalorie consumption. As such, it takes more resource to lift those households which are more impoverished than those which are closer to the minimum recommended kcal per capita per day. The survey result has identified that the relative deficiency among food insecure households is 25.6 percent. Hence, FGT2 index shows food consumption inequality in a generic sense.

Moreover, headcount ratio, depth of food insecurity and its severity has shown significant variation across sample agro-climatic zones. The head count ratio, depth of food insecurity, and its severity index, on average, accounted $67.12,33.58$, and 21.98 percent for highland, 78.12 , 47.46, and 35.53 percent lowland, and $60.87,20.67$, and 9.48 percent for mid-highland agro-ecological zones. Thus, the extent of food insecurity in lowland is severe than the rest of two agro-climatic zones.

Decomposing the incidence, depth and severity of food insecurity indices across different household characteristics is a critical part of food insecurity analysis such that it is believed to help policy makers to better understand the existing variation in the extent of food insecurity among households and hence for targeting. Table 4 below presents the computed value of head count index, food insecurity gap (shortfall or depth of food insecurity) and severity of food insecurity by the demographic and socio-economic characteristics of households as discussed in previous section.

Accordingly, the result has revealed that food insecurity was high for age group 35-to-44 years with the headcount index, short-fall index and severity of $37.17,20.64$, and 15.72 percent, respectively. Subsequently, as age increased, the FGT indices have showed the

\begin{tabular}{|c|c|c|c|c|c|c|c|c|}
\hline Group & Freq. & Percent & \multicolumn{4}{|c|}{ Per capita kilocalorie Consumption per day } \\
\cline { 4 - 8 } & & & Mean & Min & Max & Std. Err & [95\% Conf. Interval] & t statistic \\
\hline Food secure & 47 & 29.38 & 2468.44 & $2,202.94$ & 3457.75 & 47.10578 & {$[2373.619,2563.257]$} \\
\hline Food insecure & 113 & 70.62 & 1494.425 & 976.26 & 2194.03 & 27.74339 & {$[1439.455,1549.395]$} \\
\hline Combined & 160 & 100 & 1780.541 & 976.26 & 2194.03 & 42.53632 & {$[1696.532,1864.55]$} & Prob> t=0.0000 \\
\hline Difference & & & 974.0125 & & & & {$[870.0223,1078.003]$} \\
\hline
\end{tabular}

Table 1: Summary of descriptive statistics.

\begin{tabular}{|c|c|c|c|c|c|c|c|}
\hline Agro-ecology & Sum & Min & Max & Mean & Std. Dev. & Freq. \\
\hline Mid-highland & 47481.28 & 1372.77 & 3217.75 & 2064.404 & 566.6044 & 23 \\
\hline Highland & 133498.9 & 1104.78 & 3457.75 & 1828.752 & 546.5474 \\
\hline Lowland & 103906.4 & 976.26 & 2844.35 & 1623.538 & 469.0196 \\
\hline Total & 284887.6 & & & 1780.547 & 538.0466 & 43 \\
\hline
\end{tabular}

Table 2: Summary statistics of variation in dietary energy available per AE per day by Agro-ecology.

\begin{tabular}{|c|c|c|c|c|}
\hline Source & SS & df & MS & Prob> F \\
\hline Between groups & 3600571 & 2 & 1800286 & 6.66 \\
\hline Within groups & 42429003 & 157 & 270248.4 & \\
\hline Total & 46029575 & 159 & 289494.2 & \\
\hline Source: Field Survey, February 2015 & & & \\
\hline
\end{tabular}

Table 3: Analysis of variance (ANOVA). 


\begin{tabular}{|c|c|c|c|}
\hline FGT classes & Highland & Lowland & Midland \\
\hline FGT0 [ P0 ] & 0.6712 & 0.7812 & 0.6087 \\
\hline FGT1 [ P1] & 0.3358 & 0.4746 & 0.2067 \\
\hline FGT2 [ P2 ] & 0.2198 & 0.3553 & 0.7062 \\
\hline Source: Field Survey, February 2015 & & & 0.0948 \\
\hline
\end{tabular}

Table 4: FGT class of food insecurity measures across sample Agro-ecological zones.

declining trend in the extent of food insecurity. This might be due to the superior asset ownership, like landownership status of households with relatively old aged head.

The then established land tenure system in Ethiopia, i.e., 30 years before, that continued to operate until now and the current government's policy stance that highly favours investors than landless rural and urban youths in one aspect, and lack of any hope for future land reform on the other aspect, clearly justifies the statement that younger age groups are inferior to their counter parts with regard to an ownership of essential factor of production and hence it is likely that the extent of food insecurity would be severe among these groups. Accordingly, this result is consistent with many food security related research works based on rural study areas.

However, the above result is inconsistent with previous research work by Girma [19]. The reason for inconsistency may be due to the fact that the study has been undertaken in city and hence many household characteristics in city and country side are nearly unrelated. Considering the average adult equivalent family size of food insecure household groups as a cut-off point, the estimated result shows that food insecurity is more severe in households with larger family size than the group average with headcount, short-fall and severity indices of 46.9 percent, 31.11 percent and 23.4 percent, respectively. This indicates that food insecurity worsen as household size increased and confirms the prior expectation. Households with the dependency ratio higher than the group average are also in severe food shortage compared to their counterparts.

The indices for sex of household head shows that food insecurity was worse in male headed household with food insecurity headcount index, short-fall index and severity of $80.53,39.59$, and 25.86 percent, respectively than the female counterparts having head count index of 19.47 percent, short-fall index of 13.19 percent, and the severity index of 10.40 percent. This result is, however, inconsistent with the prior expectation and empirical findings by different researchers. The reason as discussed in previous section may be due to the fact that few numbers of female headed households were included in the sample survey.

With regard to educational status of the household head, the food insecurity was concentrated in the group with illiterate household head having an estimated headcount ratio, short-fall and severity index of $63.72,33.7$, and 23.11 percent, respectively. High indices of food insecurity were also recorded for households who were not engaged in off-farm activities than those engaged in off-farm income generating activities with headcount ratio of 65.49 percent, short-fall index of 38.44 percent, and severity index of 27.07 percent. In the same manner, the computed result as presented in Table 4 above has shown that the extent of food insecurity was relatively severe in those groups who lack access to rural credit, don't get remittance income, and lives far away from the local market.

Another important aspect of analysis is looking the variation in household's food security status in terms of land size and livestock ownership. The estimated food insecurity headcount ratio, short-fall and severity for households with land size less than the food insecure group average were $58.41,37.97$, and 29.17 percent, respectively. The indices computed to detect if there is any variation within food insecure groups revealed that households who own less than the group average livestock unit were found more prone to severe food insecurity with the estimated food insecurity head count, short-fall and severity indices of 46.9, 29.73, and 22.65 percent, respectively. For their counterparts who own greater than the group average livestock unit, the head count index of 53.10 percent, short-fall index of 23.05 percent, and the severity index of 13.6 percent was computed.

\section{Indices of coping strategies}

Table 5 below presents the types of coping strategies adopted by sample households in the study area as determined by focus group discussion during the survey period. As was discussed in section two, the coping strategies are those strategies used by households during the period of hungry seasons. The types of strategies used have an important implication for assessing food security situation. This is so because some coping mechanisms may destroy the future livelihood of the households and indicate the future vulnerability to food insecurity.

The coping strategy index was initially developed and used by World Food Program as a rapid food security assessment tool. Accordingly, in the present study, the Coping Strategy Index for each sample household was computed by combining the frequency and severity of strategies adopted to see the likely difference between the food security groups with respect to these strategies.

The survey result identified the ten most commonly used strategies for households to cope with shortage of food access. These include: relying on less preferred and less expensive foods, borrowing food, purchase food on credit, skipping meals for adults to feed children instead, reducing the number of meal per day, limiting portion size during meal, skip entire days without eating, consuming seed stock held for next season, selling productive assets, and distress migration. The 80 percent of sample households reported relying on less preferred and less expensive foods and 58.75 percent of households reported limiting portion size during meal. The third highest reported coping strategy is selling productive assets (41.88 percent), followed by reducing the number of meal per day (35.63 percent).

Among those strategies, the most severe strategy is selling household productive assets and it was used by 65.67 percent of food insecure households while 34.33 percent of food secure households also adopted the same strategy. However, most of the coping strategies, even if they are reversible, can have a permanent cost on lives and livelihoods through poorer health and nutritional status in the future.

The mean coping strategy score (index) for food secure and food insecure households were found to be 45.74 and 57.69, respectively. The likely difference between the means was tested and the t-statistic was found to be 6.5827 reflecting the existence of statistically significant difference between the mean. Hence, we can conclude that the type of coping strategy used by food secure and insecure groups is significantly different. Table 6 below presents details for these issues. 
Citation: Gazuma EG (2018) An Empirical Examination of the Determinants of Food Insecurity among Rural Farm Households: Evidence from Kindo Didaye District of Southern Ethiopia. Bus Eco J 9: 345. doi: 10.4172/2151-6219.1000345

Page 8 of 12

\begin{tabular}{|c|c|c|c|}
\hline Variables & Incidence of food insecurity (Head count index) & Food insecurity gap (Short-fall index) & Squared food insecurity gap (Severity index) \\
\hline \multicolumn{4}{|c|}{ HH Head Age } \\
\hline $25-34$ & 0.1327 & 0.0667 & 0.0398 \\
\hline $35-44$ & 0.3717 & 0.2064 & 0.1572 \\
\hline $45-54$ & 0.2301 & 0.1326 & 0.0969 \\
\hline $55-64$ & 0.1947 & 0.0969 & 0.0609 \\
\hline$>65$ & 0.0708 & 0.0253 & 0.0137 \\
\hline \multicolumn{4}{|c|}{ Sex of Household Head } \\
\hline Male & 0.8053 & 0.3959 & 0.2586 \\
\hline Female & 0.1947 & 0.1319 & 0.104 \\
\hline \multicolumn{4}{|c|}{ HH Head Education } \\
\hline Literate & 0.3628 & 0.1908 & 0.1314 \\
\hline Illiterate & 0.6372 & 0.337 & 0.2311 \\
\hline \multicolumn{4}{|c|}{ Household Size (in AE) } \\
\hline$<5.81$ & 0.531 & 0.2167 & 0.1285 \\
\hline$\geq 5.81$ & 0.469 & 0.3111 & 0.234 \\
\hline \multicolumn{4}{|c|}{ Dependency Ratio } \\
\hline$<1.41$ & 0.5044 & 0.2351 & 0.1529 \\
\hline$\geq 1.41$ & 0.4956 & 0.2927 & 0.2096 \\
\hline \multicolumn{4}{|l|}{ Land Size } \\
\hline$\geq 0.175$ & 0.4159 & 0.1481 & 0.0709 \\
\hline$<0.175$ & 0.5841 & 0.3797 & 0.2917 \\
\hline \multicolumn{4}{|c|}{ Livestock Owned } \\
\hline$\geq 2.73$ & 0.531 & 0.2305 & 0.136 \\
\hline$<2.73$ & 0.469 & 0.2973 & 0.2265 \\
\hline \multicolumn{4}{|c|}{ Off-Farm Activity } \\
\hline Yes & 0.3451 & 0.1434 & 0.0918 \\
\hline No & 0.6549 & 0.3844 & 0.2707 \\
\hline \multicolumn{4}{|c|}{ Remittance } \\
\hline Yes & 0.4867 & 0.2382 & 0.15 \\
\hline No & 0.5133 & 0.2895 & 0.2125 \\
\hline \multicolumn{4}{|c|}{ Distance to the Market } \\
\hline$<41.23$ & 0.4513 & 0.2126 & 0.1369 \\
\hline$\geq 41.23$ & 0.5487 & 0.3152 & 0.2256 \\
\hline \multicolumn{4}{|c|}{ Access to Credit } \\
\hline Yes & 0.2655 & 0.1291 & 0.085 \\
\hline No & 0.7345 & 0.3987 & 0.2774 \\
\hline
\end{tabular}

Table 5: Decomposition of FGT indices by selected by socio-economic characteristics of households.

\begin{tabular}{|c|c|c|c|c|c|c|c|c|}
\hline \multirow[t]{2}{*}{ The Type of Coping Strategy Used } & \multirow[t]{2}{*}{ Freq. } & \multirow{2}{*}{$\begin{array}{l}\text { Freq. } \\
\text { Weight }\end{array}$} & \multicolumn{2}{|c|}{ Food secure } & \multicolumn{2}{|c|}{ Food insecure } & \multicolumn{2}{|c|}{ Total } \\
\hline & & & Freq. & Percent & Freq. & percent & Freq. & percent \\
\hline Rely on Less Preferred And Less Expensive Foods & 128 & 1 & 35 & 27.34 & 93 & 72.65 & 128 & 80 \\
\hline Limit Portion Size at Mealtimes & 94 & 1 & 33 & 35.11 & 61 & 64.89 & 94 & 58.75 \\
\hline Purchase Food on Credit & 48 & 2 & 16 & 33.33 & 32 & 66.67 & 48 & 30 \\
\hline Borrow Food, or Rely on Help from Friends or Relatives & 36 & 3 & 0 & - & 36 & 100 & 36 & 22.5 \\
\hline Skipping Meals for Adults to Feed Children Instead & 53 & 2 & 12 & 22.64 & 41 & 77.36 & 53 & 33.13 \\
\hline Reducing the Number of Meal Per Day & 57 & 2 & 9 & 15.79 & 48 & 84.21 & 57 & 35.63 \\
\hline Skip Entire Days Without Eating & 19 & 4 & 0 & - & 19 & 100 & 19 & 11.88 \\
\hline Consume Seed Stock Held For Next Season & 54 & 3 & 19 & 35.19 & 35 & 64.81 & 54 & 33.75 \\
\hline Sell Productive Assets & 67 & 4 & 23 & 34.33 & 44 & 65.67 & 67 & 41.88 \\
\hline Distress Migration & 12 & 4 & 0 & - & 12 & 100 & 12 & 7.5 \\
\hline
\end{tabular}

Table 6: Frequency of coping strategies adopted by food security status

\section{Econometric analysis of the determinants of food insecurity}

In section two, the researcher has explored the mechanics of data analysis using Logistic regression model in order to examine the correlates of food insecurity. Accordingly, sixteen variables assumed to have influence on households' food security situation were included in the model. These variables include: agro-ecology, age, sex, and literacy status of the household head, household size, dependency ratio, livestock ownership, cultivable land size, engagement in off-farm income generating activities, remittance from migrant family member, 
proximity to the nearest local market, participation in community institutions (proxied by membership in 'Equb'), technology adoption (proxied by use of chemical fertilizer), access to credit, participation in productive safety net programs, and access to adequate extension services. Consequently, six variables out of sixteen were found significant determinants of food security situation in the study area. Thus, this section presents the estimation result of the binary logit model and its interpretation.

An essential part of any regression analysis involves the diagnostics checking before fitting the model. As such, the likely existence of multi co-linearity among the explanatory variables was checked by computing the Variance Inflating Factor (VIF) and Contingency coefficients (C). The regression diagnostics result of VIF for each of the continuous explanatory variables was found to be significantly less than the standard cut off value of 10 and revealed the none-existence serious multi co-linearity problem among the continuous variables included in the model. The diagnostics check results of $\mathrm{C}$ also shown very lower values than the standard value of 0.75 and hence confirmed that there was no serious problem of co-linearity among discrete independent variables included in the model. As a result, all sixteen variables were fitted in the logistic regression model.

After fitting the model, the post-estimation diagnostics checks were undertaken to evaluate the overall model. A logistic model is said to provide a better fit to the data if it demonstrates an improvement over the intercept-only model (also called the null model, which has no predictors). Consequently, such an improvement is usually examined by the Likelihood Ratio (LR) test. It tests the null model which tells us that none of the explanatory variables are linearly related to the $\log$ odds of the dependent variable i.e., food security status in this case. The LR follows the chi-square distribution with the degree of freedom equals the number of predictors and hence with the $\mathrm{LR} \mathrm{chi}^{2}$ (16) test statistic value $=114.85$ and the $P r o b>c h i^{2}=0.0000$, the result is statistically significant at less than $1 \%$ level of significance revealing that the null hypothesis can be rejected.

Moreover, the goodness of fit statistic is used to assess a logistic model against the data. For the present study, it is measured by Pearson's chi-square test. Pearson's chi-square test result reported a chi-square value of 227.97 with p-value of 00.0000 on 143 degrees of freedom and confirmed that there is no difference between the observed and the model predicted values and hence estimates of the model fit the data at less than $1 \%$ level of probability.

Table 7 presents the maximum likelihood estimates of the logit model. The estimation result was interpreted by marginal effects as it is much superior to the coefficients and/or odds ratio. For categorical variables, the effects of discrete changes are computed, i.e., the marginal effects for categorical variables show how $\mathrm{P}(\mathrm{Y}=1)$ is predicted to change as binary explanatory variable, say $\mathrm{Xk}$ changes from 0 to 1 holding all other Xs equal. Consequently, the model result has indicated that out of sixteen variables fitted into the model, six were found statistically significant predictors of households' food insecurity. These include household size, sex of the household head, farm land size, livestock ownership, engagement in off-farm activities, and proximity to the market.

Household size (HHsize): The model result has revealed that there is a positive relationship between the size of household and their probability of being food insecure. In other words, it is to mean that as family size increases, the probability of being food insecure also increases marginally, holding other things remaining the same. As the model result presented in Table 7 above shown, for a unit increase in the family size of a household increases the likelihood of being food insecure by 4.45 percent. This might be attributed to the prevalence of large number of non-productive age members in a household thereby increasing the dependency ratio of the household. The result is statistically significant at less than $1 \%$ level of significance and hence confirmed the prior expectation. This result is also consistent with several empirical findings of various studies [36-38].

Sex of the household head (HHHsex): According to the estimation result, male headed households were found more food insecure than the female headed households. This result is contrary to what was expected and perhaps theoretically difficult to interpret. It was found statistically significant at $10 \%$ level of significance with the associated positive relationship between sex of household heads and food insecurity. It means that being male headed increases the likelihood of food insecurity by 17.59 percent, all other things being equal. During the survey, it was understood that there are very few cases where females are the head of the household, and this happens when only the husband is absent or dead. The fact that relatively small number of sample female headed households included for comparison might have influenced the above result.

Distance to the nearby market (DSTNC): The results of the survey revealed that the variable under consideration is positively related with food insecurity and is significant at less than $5 \%$ level of significance. Holding other things constant, a one minute increase in distance to the local market increases the probability of being food insecure by $0.41 \%$. This result is also consistent with the expected result of the researcher and the finding of Lewin [38] which has revealed that poor

\begin{tabular}{|c|c|c|c|c|c|c|c|}
\hline \multirow{2}{*}{$\begin{array}{l}\text { Coping Strategy } \\
\text { Index (CSI) }\end{array}$} & \multicolumn{2}{|c|}{ Food Secure } & \multicolumn{2}{|c|}{ Food Insecure } & \multicolumn{2}{|c|}{ Total } & \multirow[t]{2}{*}{$|\mathbf{t}|$-Statistic } \\
\hline & Freq. & Percent & Freq. & Percent & Freq. & Percent & \\
\hline$\leq 25$ & 1 & 2.13 & - & - & 1 & 0.625 & $6.5827^{\star \star \star}$ \\
\hline $26-35$ & 9 & 19.15 & 3 & 2.65 & 12 & 7.5 & \\
\hline $36-45$ & 12 & 25.53 & 13 & 11.5 & 25 & 15.625 & \\
\hline $46-55$ & 14 & 29.79 & 29 & 25.66 & 43 & 26.875 & \\
\hline $56-65$ & 8 & 17.02 & 45 & 39.82 & 53 & 33.125 & \\
\hline $66-75$ & 3 & 6.38 & 20 & 17.7 & 23 & 14.375 & \\
\hline$>75$ & - & - & 3 & 2.65 & 3 & 1.875 & \\
\hline Total & 47 & 100 & 113 & 100 & 160 & 100 & \\
\hline Mean CSI & 45.74 & & 57.69 & & 54.18125 & & \\
\hline Std. Dev. & 11.94 & & 9.78 & & 11.76493 & & \\
\hline
\end{tabular}

Table 7: Coping strategy index by household food security status. 
transport infrastructure accounts for up to 55 percent of marketing cost. The possible explanation is that the result confirms the vital role of infrastructure for household food security to ensure low food prices and efficient markets that can respond to changes in demand. Infrastructure reduces the cost of transporting produce and inputs; and markets provide an important platform for farmers to gather and share information. Better rural infrastructure also promotes economic diversification by linking rural and urban sectors of the economy or the farm and non-farm economic activities.

Livestock ownership (TLU): As predicted, the result confirmed that households that are well off in terms of livestock are less likely to be energy deficient. The association between livestock holdings and household energy deficiency is also negative and significant at less than $1 \%$ level of significance in the study area. This means that a one unit increase in the number of livestock owned decreases the probability of being food insecure by 10.75 percent. Hence it is consistent with findings of previous researchers and the researcher's prior expectation [39].

Farm land size (FLsize): The area of land cultivated per capita has also statistically significant negative association with food insecurity in the study area. The interpretation here is that a one hectare increase in cultivable land reduces the probability of being food insecure by 18.44 percent; the highest marginal effect seen in the model result. This is significant at $1 \%$ level of probability and hence the existence of inverse relationship between food insecurity and the size of cultivable land confirmed the prior expectation of the researcher and other similar studies $[18,32]$.

Engagement in off-farm income generating activities (OFFarm): Off farm income generating opportunities are critical to raise household's income. Households engaged in off farm activities like petty trades in the study area were found better food secure than their counter parts. As such, engagement in off farm activities is negatively related to household's food insecurity. Keeping other things being equal, being engaged in off farm income generating activity reduces the probability of being food insecure by 17.63 percent, the second highest marginal effect among other variables included in the model, and found significant at less than $5 \%$ level of significance. Due to lack of farm land in the part of households with youth head, and the decline in soil fertility associated with frequent land degradation and consequent reduction in farm productivity on the other part, has said to necessitate many households to engage in this type of activities. This result is in line with a finding of and the researcher' prior hypothesis [15].

As per estimation result in the Table 7 above, the model result correctly predicted percentage of sample households are 89.38 percent which is much greater than 0.50 cut off predicted probability value. The sensitivity_ correctly predicted food insecure is 93.81 percent while specificity_ correctly predicted food secure is 78.72 percent. This indicates that the model has classified the food insecure and food secure correctly.

However, the result of logistic regression indicated that all government policy related variables such as access to credit, technology adoption which was proxied by farmers' use of chemical fertilizer, adequate access to extension service, and participation in productive safety net program, all had no effect on the probability of a household being food insecure. The coefficients were statistically insignificant (Table 8). While these results are contrary to what the researcher expected, they are in no way far away from other empirical findings [40-43]. The researcher believes that in a certain circumstances, the

\begin{tabular}{|c|c|c|c|c|c|}
\hline HFSS & Coef. & Std. Err. & $\mathbf{Z}$ & $p>|z|$ & $\begin{array}{l}\text { Marginal effect } \\
(\text { (dy/dx) }\end{array}$ \\
\hline AGROeco & 0.729406 & 0.578854 & 1.26 & 0.208 & 0.035333 \\
\hline HHHSEX & 1.94536 & 1.055237 & 1.84 & $0.065^{*}$ & 0.175939 \\
\hline HHHage & -0.023 & 0.032967 & -0.7 & 0.485 & -0.00111 \\
\hline HHHeduc & -0.19048 & 0.81822 & -0.23 & 0.816 & -0.00946 \\
\hline HHSIZE & 0.918484 & 0.304999 & 3.01 & $0.003^{\star * \star}$ & 0.044492 \\
\hline DPNDCYratio & 0.620288 & 0.801617 & 0.77 & 0.439 & 0.030047 \\
\hline TLU & -2.22003 & 0.491325 & -4.52 & $0.000^{* \star *}$ & -0.10754 \\
\hline FLSIZE & -3.80804 & 1.274532 & -2.99 & $0.003^{\star * \star}$ & -0.18446 \\
\hline REMITT & -0.44193 & 0.655545 & -0.67 & 0.5 & -0.02111 \\
\hline OFFARM & -1.76313 & 0.848585 & -2.08 & $0.038^{\star *}$ & -0.07756 \\
\hline SOCIALinst & 0.151992 & 0.626437 & 0.24 & 0.808 & 0.00728 \\
\hline DSTNC & 0.085483 & 0.032779 & 2.61 & $0.009^{* * *}$ & 0.004141 \\
\hline CRDTacc & 0.084922 & 0.671452 & 0.13 & 0.899 & 0.00405 \\
\hline TECHadopt & -0.96558 & 0.899664 & -1.07 & 0.283 & -0.0366 \\
\hline EXTNacc & -0.52404 & 0.886457 & -0.59 & 0.554 & -0.02175 \\
\hline PSNP & 0.165238 & 0.73239 & 0.23 & 0.822 & 0.007747 \\
\hline -Cons & 3.954952 & 3.018468 & 1.31 & 0.19 & \\
\hline \multicolumn{5}{|c|}{ Number of Observation } & 160 \\
\hline \multicolumn{5}{|c|}{ LR PEARSON CHI^2(16) } & 114.85 \\
\hline \multicolumn{5}{|l|}{ Prob > Chi2 } & 0 \\
\hline \multicolumn{5}{|l|}{ Log Likelihood } & -39.4502 \\
\hline \multicolumn{5}{|l|}{ Pseudo R2 } & 0.5928 \\
\hline \multicolumn{5}{|c|}{ Sensitivity_Correctly Predicted Food Insecure Group } & $93.81 \%$ \\
\hline \multicolumn{5}{|c|}{ Specificity_Correctly Predicted Food Secure Group } & $78.72 \%$ \\
\hline \multicolumn{5}{|c|}{$\begin{array}{l}\text { Correctly Classified Based on Predicted } \operatorname{Pr}(D)>=0.5 \text { Cut } \\
\text { Value }\end{array}$} & $89.38 \%$ \\
\hline
\end{tabular}

empirical analysis has to be supported by the qualitative analysis so that the possible reasons for statistical insignificance might be captured and future researchers might consider this gap.

\section{Conclusion and Policy Implications}

This study has examined the essential determinants of food insecurity for rural farm households in Kindo Didaye district of southern Ethiopia. The study revealed that 70.62 percent of the households in the study area were not able to meet the daily recommended minimum caloric requirement and 37 percent of the households were below the food insecurity line while 25.6 percent of the households were found the most food insecure groups in the study area. Accordingly, the peculiar characteristics of food insecure households are that they own, on average, 0.175 hectare of farm land and 2.73 tropical livestock units. Food insecure households also possess, on average 5.81, family size and large number of dependents than their counterparts.

As reported by sample respondents and some key informants, the prevailing crop production risks, such as crop failure due to pests and diseases, and lack of alternative income sources which aggravated the continued youth migration from the study area were the major features of food insecure households. Subsequently, the study has identified the major factors influencing food security of rural households through empirical investigation. These include: household size, sex of the household head, cultivable land size, livestock ownership, engagement in off-farm income generating activities, and distance to the nearby local market. The study also shown that household size, sex of the household head, and distance to the nearby local market have a significant and positive influence on the state of household food insecurity while land size, livestock ownership and engagement in off- 
farm income generating activities and food insecurity were negatively and significantly related.

The results provide insights into policy implications that have the potential to reduce food insecurity. Accordingly, Land shortage and fragmentation is supposed to be the major cause of food insecurity in the district as discussed above, even it will be a continuing challenge in the future. Therefore, mechanism should be devised to divert surplus labor from land to non-land intensive production systems like small enterprises or a way forward for resettlement should be sought.

Livestock sector development should also be a priority to help alleviate food insecurity since livestock number and oxen ownership were significant causes of food security. In this aspect, livestock development packages must be introduced and promoted.

For the fact that family size is a basic cause of food insecurity, attention has to be given to limit the increasing population in the study area. This can be achieved by creating sufficient awareness to improve family planning in the rural households. Policies aimed at reducing costs of food and farm inputs were also shown to reduce the probability of food insecurity in different literatures. Therefore, it is important to ensure that these policies target the poorest farmers, are cost effective and fiscally sustainable, and avoid negative impacts on private sector participation. Farmers need reliable access to markets for selling and purchasing products.

The study has concluded that food insecurity increases with increasing distance from a nearby market. This calls for alternative public transport facility. However, road infrastructure in the study area is nearly nonexistent and perhaps the lowest in Southern Ethiopia. Investment in transport infrastructure, particularly roads linking farmers to markets, would reduce costs of crop production and transport can increase farmers' ability to buy inputs and sell outputs.

Production in the study area is solely dependent on rainfall. Due to its unfavourable topography for agriculture, the usual summer rainfall erodes the crops in the field and further aggravates the food security situation of the study area. Hence, the government policy should be directed towards tackling the recurring problem of land degradation through conservation mechanisms in the study area. The district is one of the most drought affected areas in southern Ethiopia. Irrigation infrastructure is believed to reduce impacts of adverse weather. However, this calls for government' high policy concerns as irrigation schemes in river drought areas like the study area needs huge investment.

In addition to transport and irrigation infrastructure, government investment in agricultural extension activities is believed to have a significant impact on food security. However, the present study has found insignificant relationship between access to extension services and food security. This might be because of development agents' motivational issues and the subsequent lack of monitoring and evaluation on behalf of the government. The farmers training centers haven't started the normal operation yet but the centers were there. Thus, government policy should give attention to training and advisory services apart from provision of technology so as to improve the food security situation in the study area.

\section{Acknowledgement}

My first thank is to the Almighty God who guided me throughout my life with his care and blessings. Special thanks to Dr. Solomon Alemu without whom it would have been difficult for me to accomplish this work. His persistent guidance and encouragement during this work was certainly the best I could have. My next sincere gratitude goes to Bureau of Finance and Economic Development of Wolaita Zone Administration for providing me necessary statistical data pertaining to Kindo Didaye district. I am also thankful to Merdkiyos, Thomas, and Teshome for their massive support during data collection. I am indebted to my distinguished ex-staffs of Ethiopian Revenues and Customs Authority Adama Branch Office for their invaluable contribution to my study. Finally, I am grateful to my family for their deep motivation and financial supports.

\section{References}

1. FAO (1996b) Rome Declaration on World Food Security and World Food Summit Plan of Action. Document prepared at the World Food Summit, Rome.

2. UN (2007) Dignity and justice for all of us. $60^{\text {th }}$ Anniversary special edition United Nations Department of Public Information.

3. FAO (2014) The State of Food and Agriculture: Innovation in Family Farming Food and Agriculture Organization of the United Nations, Rome.

4. UNDP (2013) Annual report. United Nations Development Programme in Ethiopia.

5. USAID (2014) New Alliance for Food Security and Nutrition: Annual Progress Review (2013-2014) Report.

6. NIP (2014) National Indicative Programme for Ethiopia 2014 to 2020 The Government of Ethiopia and the-European Commission Cooperation Agreement. 19 June 2014, Nairobi.

7. MoFED (2010/11) Growth and Transformation Plan (GTP) (2010/11-2014/15).

8. CSA \& WFP (2014) Comprehensive Food Security and Vulnerability Analysis (CFSVA). A joint publication between the CSA and the World Food Programme.

9. FAO, IFAD and WFP (2014) The State of Food Insecurity in the World 2014 Strengthening the enabling environment for food security and nutrition. Rome, FAO.

10. CSA (2014) Ethiopian Mini Demographic and Health Survey (EMDHS). (2014) Central statistical Authority of Ethiopia. Survey report, 2014.

11. WFP (2009) Emergency Food Security Assessment Handbook. $2^{\text {nd }}$ edition WFP Food Security Analysis Service

12. Kebebew $F$ (2014) Food insecurity and the relative importance of various household assets: the case of farm households in Southern Ethiopia. Master's Thesis. Swedish University of Agricultural Studies.

13. Devereux S (2000) Food Insecurity in Ethiopia. A discussion paper for DFID.

14. Shishay K, Messay M (2014) Determinants of rural household food insecurity in Laelay Maichew Woreda Tigray, Ethiopia. African Journal of Agriculture and Food Security 2: 106-112.

15. Amsalu M, Bekabil F, Beyene T (2013) Analysis of factors Determining Households Food Security in Pastoral Area of Oromia Region, Moyale District ,Ethiopia. International Journal of Agricultural Science, Research and Technology 2: 105-110.

16. MoFED (2013) Development and Poverty in Ethiopia (1995/96-2010/11). Addis Ababa.

17. Zerihun N, Getachew A (2013) Levels of Household Food Insecurity in Rural Areas of Guraghe zone, Southern Ethiopia. Wudpecker Journal of Agricultural Research 2: 008-014.

18. Adugna E, Wagayehu B (2012) Causes of Household Food Insecurity in Wolaita. Journal of Stored Products and Postharvest Research 3: 35-48.

19. Girma G (2012) Determinants of Food Insecurity among households in Addis Ababa City, Ethiopia. Interdisciplinary Description of Complex Systems 10: 159-173.

20. Meseret MG (2012) Household Food Security Status and Coping Strategies in Humbo Woreda, SNNPRS, Ethiopia. International Journal of Sciences: Basic and Applied Research 6: 64-82

21. Bechaye T (2011) Rural Household Food Security Situation Analysis: the case of Boricha Woreda in Sidama Zone. Unpublished Master's thesis. Addis Ababa University.

22. Meskerem A (2011) Household Food Security Situation in Girar Jarso Woreda North Shewa zone of Oromia Regional State, Ethiopia.

23. Tsegay G (2009) Determinants of Food Security in Rural Households of the Tigray Region. Unpublished Master's thesis. Addis Ababa University. 
Citation: Gazuma EG (2018) An Empirical Examination of the Determinants of Food Insecurity among Rural Farm Households: Evidence from Kindo Didaye District of Southern Ethiopia. Bus Eco J 9: 345. doi: 10.4172/2151-6219.1000345

24. BoFED (2013/14) Annual Socio-economic and Demographic Reports. Development Data Collection and Dissemination Core Process, Bureau of Finance and Economic Development of Wolaita Zone.

25. Kothari CR (2004) Research methodology: Methods and Techniques. $2^{\text {nd }}$ revised edition. New age international publishers.

26. CSA (2012) Ethiopian Households Consumption -Expenditure (HCE) Survey (2010/11).

27. Chen S, Ravallion M (2008) The Developing World is Poorer than We Thought, but no Less Successful in the Fight against Poverty. The Quarterly Journal of Economics 125: 1577-1625.

28. EHNRI (2000) Food Consumption Table for Use in Ethiopia. Ethiopia Health and Nutrition Research Institute (EHNRI), Addis Ababa, Ethiopia.

29. Foster J, Greer J, Thorbecke E (1984) A Class of Decomposable Poverty Measures. Econometrica 52: 761-766.

30. Maxwell DG (1996) Measuring Food Insecurity: The frequency and severity of coping strategies. Food Policy 21: 291-303.

31. Maxwell D, Ahiadeke C, Levin C, Armar-Klemesu M, Zakariah S, et al. (1999) Alternative Food-Security Indicators: Revisiting Frequency and Severity of 'Coping Strategies'. Food Policy 24: 411-429.

32. Tagel G (2012) Food Security Policy: Does it work? Does it help? University of Twenty. The Netherlands

33. Bickel G, Nord M, Price C, Hamilton W, Cook J (2000) Guide to Measuring Household Food Security. United States Department of Agriculture (USDA).
34. Wooldridge JM (2002) Econometric Analysis of Cross Sectional and Panel Data. The MIT Press.

35. Gujarati DN (2004) Basic Econometrics. Fourth Edition. The McGraw-Hil companies.

36. Babatunde RO, Omotsho OA Sholatan OS (2007) Socioeconomic Characteristics and Food Security of Farming Households in Kwara State, North Central Nigeria. Pak J Nutr 6: 49-58.

37. Osei MJ, Aidoo R, Tuffour T (2013) Determinants of household Food Security in the Sekyere-Afram Plains District of Ghana. Global Advanced Research Journal of Agricultural Science.

38. Lewin P (2011) Food Security, Food Assistance, and Migration. A dissertation submitted to Oregon State University.

39. Kidane HH, Alemu ZG, Kundhlande G (2005) Causes of Household Food Insecurity in Koredegaga Peasant Association, Oromia Region, Ethiopia. Agrekon.

40. FAO (2011) Assessing Impact of Development Programmes on Food Security Food Security Concepts and Frameworks.

41. Haddad L, Achadi E, Bendech MA, Ahuja A, Bhatia K et al. (2015) Global Nutrition Report 2014: Actions and Accountability to Accelerate the World's Progress on Nutrition. The Journal of Nutrition 145: 663-671.

42. Johnston A (2013) Methods/Stata Manual for School of Public Policy. Journal of Stored Products and Postharvest Research.

43. Krishnamurthy PK, Hobbs C, Matthiasen A, Hollema SR, Choularton RJ, et al (2013) Climate risk and food security in Ethiopia: Analysis of climate impacts on food security and livelihoods. A Repository of Agriculture Research Outputs. 